\title{
Nano-emulsions as vehicles for topical delivery of forskolin
}

\author{
Małgorzata Miastkowskaํ, Elżbieta Sikora1凶, Elwira Lasoń1, Maria Jose Garcia-Celma², \\ Elvira Escribano-Ferrer², Conxita Solans ${ }^{3}$ and Meritxell Llinas ${ }^{3}$
}

1Institute of Organic Chemistry and Technology, Cracow University of Technology, Kraków, Poland; 2 Pharmacy and Pharmaceutical Technology Department, Faculty of Pharmacy, University of Barcelona, Barcelona, Spain, IN $\mathrm{N}_{2} \mathrm{UB}$ members; ${ }^{3}$ Institute of Advanced Chemistry of Catalonia, Consejo Superior de Investigaciones Científicas (IQAC-CSIC) and CIBER en Bioingeniería, Biomateriales y Nanomedicina (CIBER-BBN), Barcelona, Spain

Two O/W forskolin-loaded nano-emulsions ( $0.075 \%$ wt.) based on medium chain triglycerides (MCT) and stabilized by a nonionic surfactant (Polysorbate 80 or Polysorbate 40) were studied as forskolin delivery systems. The nano-emulsions were prepared by the PIC method. The mean droplet size of the nano-emulsions with Polysorbate 80 and Polysorbate 40 with oil/surfactant (O/S) ratios of $20 / 80$ and $80 \%$ water concentration, measured by Dynamic Light Scattering (DLS), was of $118 \mathrm{~nm}$ and $111 \mathrm{~nm}$, respectively. Stability of the formulations, as assessed by light backscattering for $24 \mathrm{~h}$, showed that both nano-emulsions were stable at $25^{\circ} \mathrm{C}$. Studies of forskolin in vitro skin permeation from the nano-emulsions and from a triglyceride solution were carried out at $32^{\circ} \mathrm{C}$, using Franz-type diffusion cells. A mixture of PBS/ ethanol $(60 / 40 \mathrm{v} / \mathrm{v})$ was used as a receptor solution. The highest flux and permeability coefficient was obtained for the system stabilized with Polysorbate $80(6.91 \pm 0.75$ $\mu \mathrm{g} \cdot \mathrm{cm}^{-2} \cdot \mathrm{h}^{-1}$ and $9.21 \cdot 10^{-3} \pm 1.00 \cdot 10^{-3} \mathrm{~cm} \cdot \mathrm{h}^{-1}$, respectively) but no significant differences were observed with the flux and permeability coefficient value of forskolin dissolved in oil. The obtained results showed that the nano-emulsions developed in this study could be used as effective carriers for topical administration of forskolin.

Key words: Forskolin, nano-emulsions, medium chain triglycerides, in vitro skin permeation

Received: 05 October, 2017; revised: 13 November, 2017; accepted: 19 November, 2017; available on-line: 13 December, 2017

e-mail: esikora@pk.edu.pl

Abbreviations: DLS, Dynamic Light Scattering; F, forskolin; Jss, flux at steady state; $K_{\mathrm{p}}$, permeability coefficient; $M C T$, medium chain triglycerides; $\mathrm{NE}$, nano-emulsion; $\mathrm{O}$, oil; $\mathrm{S}$, surfactant; $\mathrm{O} / \mathrm{S}$, oil/surfactant; O/W, oil/water; PBS, phosphate-buffered saline; PIC, Phase Inversion Composition; PDI, Polydispersity Index; $\mathrm{P}_{1}$, partition parameter; $\mathrm{P}_{2}$, diffusion parameter TEWL, Transepidermal Water Losses; $T_{L}$, lag time; $W$, water

\section{INTRODUCTION}

Forskolin is one of the labdane diterpenoids. It is isolated from the roots of Coleus Forskohlii, an aromatic herb belonging to the family of mints and lavenders, originating from India. Forskolin shows ability to activate adenylate cyclase, resulting in increased levels of cyclic adenosine monophosphate (cAMP) (Bagchi \& Preuss, 2012). It displays a broad spectrum of biological activities in the skin (Ciotonea \& Cernătescu, 2010), e.g. forskolin protects keratinocytes from UVB-induced apoptosis (Passeron et al., 2009), and also influences eumelanin production in the epidermis (Spry et al., 2009; Amaro-Ortiz et al., 2014), inducing pigmentation, and providing effective skin protection against UVB-induced DNA damage and skin cancer.

In our previous work, we reported forskolin skin permeation from $\mathrm{O} / \mathrm{W}$ emulsions with the same composition but differing in droplet size $(10 \mathrm{~mm}$ and $380 \mathrm{~nm})$ (Sikora et al., 2015). Both, macro- and nano-emulsion were prepared by a high-energy method. The obtained results showed that forskolin incorporated in the emulsions penetrates the human skin at a high percentage. Currently, nano-emulsions are being studied as effective formulations for pharmaceutical or cosmetic products (Chaudhri et al., 2015). They are liquid, kinetically stable colloidal dispersions, consisting of an aqueous phase, an oil phase and a surfactant, with or without co-surfactant. As literature reports, the droplet size of nano-emulsions internal phase is in the range from 20 to $500 \mathrm{~nm}$ (Fernandez et al., 2004; Usón et al., 2004; Kothekar et al., 2006; Porras et al., 2008; Caldero et al., 2011). From an application point of view, nano-emulsions present some advantages, among others, they are easy to spray and spread, moreover they show capacity to deposit uniformly on substrates. As pharmaceutical or cosmetic systems, they show some advantages comparing to classical emulsions, e.g. long term stability and ability to solubilize many compounds that are usually poorly soluble or insoluble in water and/or oil (Gugliemini, 2006). The major advantage of the nano-emulsions with respect to conventional emulsions, is their small droplet size. This parameter may enhance the percutaneous penetration of active substances, as well as their local bioavailability.

Surface active agents have been used to enhance the permeation rates of active substances through the skin. They cause modification of the skin barrier structure by solubilization of the stratum corneum lipids and interaction with keratin filaments (Nokhodchi et al., 2003; Som et al., 2012; Pandey et al., 2014). The penetration of the surfactant molecule into the lipid area is strongly dependent on their properties (Som et al., 2012). The most popular nonionic surfactants used to stabilize nano-emulsions are Polysorbates. They are a class of ethoxylated fatty esters of sorbitan that possess low toxicity and skin irritation potential contrary to anionic and cationic surfactants. Among all types of Polysorbates, polyoxyethylene sorbitan monooleate (Polysorbate 80) is the most effective, most widely used, as skin penetration enhancer of lipophilic drugs (Wu et al., 1996; Akhtar et al., 2011; Pandey et al., 2014). Furthermore the influence of Polysorbate 80 facilitating crossing of the blood brain barrier was reported (Wohlfart et al., 2012; Fornaguera et al., 2015).

For these reasons, in our work we have prepared forskolin-loaded $\mathrm{O} / \mathrm{W}$ nano-emulsions by low-energy 
Table 1. Physical properties of the surfactants (Graca et al., 2007).

\begin{tabular}{|c|c|c|}
\hline Commercial name & Polysorbate 80 & Polysorbate 40 \\
\hline Chemical name & $\begin{array}{l}\text { Polyoxyethylene } \\
\text { (20) sorbitan mo- } \\
\text { nooleate }\end{array}$ & $\begin{array}{l}\text { Polyoxyethylene (20) } \\
\text { sorbitan monopal- } \\
\text { mitate }\end{array}$ \\
\hline $\begin{array}{l}\text { Molecular weight } \\
{\left[\mathrm{g} \cdot \mathrm{mol}^{-1}\right]}\end{array}$ & 1310 & 1284 \\
\hline Density $\left[\mathrm{g} \cdot \mathrm{ml}^{-1}\right]$ & 1.064 & 1.080 \\
\hline $\mathrm{CMC}[\mathrm{mM}]$ & 0.012 & 0.027 \\
\hline HLB & 15.0 & 15.6 \\
\hline $\begin{array}{l}\text { Viscosity at } 25^{\circ} \mathrm{C} \\
\text { [mPas] }\end{array}$ & 425 & 500 \\
\hline Appearance & Viscous liquid & Liquid-gel \\
\hline
\end{tabular}

methods, using medium chain triglycerides (caprylic/capric triglycerides) as an oil phase and stabilized by Polysorbates differing in the alkyl chain length (Polysorbate 80, Polysorbate 40). The influence of the kind of surfactant on in vitro forskolin permeation through human skin from the nano-emulsions was evaluated.

\section{MATERIALS AND METHODS}

Materials. Nonionic surfactants, Polysorbate 80 and Polysorbate 40 purchased from Sigma-Aldrich Sp. z o.o. (Poznan, Poland) were used (Table 1). The surfactant selection was made because of its good performance and lack of irritation and toxicity to the skin. The oil used, Labrafac $C^{\circledR}$ (Medium Chain Triglycerides), abbreviated as MCT was kindly supplied by Gattefosse (Montesquieu, France). Milli-Q ${ }^{\circledR}$ filtered water was used as the aqueous phase of the emulsions. Forslean CG (Coleus Forskohlii Root Extract containing 95\% of forskolin) was purchased from Sabinsa Europe $\mathrm{GmbH}$ (Langen, Germany).

Preparation of the $\mathrm{O} / \mathrm{W}$ nano-emulsions. $\mathrm{Na}$ no-emulsions were prepared using the phase inversion composition (PIC) method by stepwise water addition to mixtures of oil (MCT) and surfactant (either Polysorbate 80 or Polysorbate 40) with ratios between 90:10 and 50:50, at $25^{\circ} \mathrm{C}$. Formation of transparent liquid phases was observed visually. Samples were considered as nano-emulsions when regardless of their viscosity they were transparent or transparent-bluish. It was confirmed that the obtained systems were not microemulsions because, in contrast to the microemulsions, their stability depended on the preparation method.

Nano-emulsion characterization and stability study. The mean droplet sizes of nano-emulsions were measured by Dynamic Light Scattering (DLS), using Malvern 4700C Sub Micron Particle Analyzer, at a scattering angle of $90^{\circ}$. The analysis was performed three times to determine the mean values and standard deviation. The emulsion stability was assessed by measuring droplet size as a function of time at constant temperature $\left(25^{\circ} \mathrm{C}\right)$.

Additionally, the nano-emulsions stability was assessed by light backscattering, by means of Turbiscan LabExpert, at a constant temperature $\left(25^{\circ} \mathrm{C}\right)$. Transmission and backscattering data were acquired for $24 \mathrm{~h}$, at 2 hour intervals, according to the method reported by Caldero and coworkers (2011).

Incorporation of forskolin into nano-emulsions. The solubility of forskolin in the oil and oil/surfactant mixtures with ratios of $20 / 80$ and $30 / 70$ was first determined. In this assay, an excess of forskolin was added to the samples and kept under moderate magnetic stirring for $24 \mathrm{~h}$, to reach equilibrium. The presence of crystals was observed by optical microscopy. In order to prepare forskolin (F) loaded nano-emulsions $(0.075 \%$ wt.) an appropriate amount of the active substance as dissolved in the oil/surfactant mixture before the addition of water to form the nano-emulsion. The samples were homogenized with a vortex mixer and then kept in a water bath at $25^{\circ} \mathrm{C}$.

Study of forskolin skin permeation. As in the previous work (Sikora et al., 2015), the in vitro skin permeation studies using the MicroettePlus ${ }^{\circledR}$ system (Hanson Research, USA) were carried out. The experiments were performed at $32^{\circ} \mathrm{C} \pm 0.5,400 \mathrm{rpm}$, and using a mixture of PBS $\mathrm{pH}=7.4 /$ ethanol $(60 / 40, \mathrm{v} / \mathrm{v})$ as the receptor medium. Abdominal human skin $(0.4 \mathrm{~mm})$ from plastic surgery (Clínica Sagrada Familia, Barcelona, Spain) and from the same donor was used. The transepidermal water losses (TEWL) of skin pieces were measured to assure the integrity of the skin. An infinite dose of formulation $(0.350 \mathrm{~mL})$ was placed in the donor compartment and samples of $700 \mu \mathrm{L}$ were withdrawn automatically from the receptor compartment at $3,6,14,16$, 18, 20, 22 and $24 \mathrm{~h}$ and replaced with the same volume of receptor mixture at $32^{\circ} \mathrm{C}$. The number of replicates per formulation was $n=4$. Permeation parameters: flux at steady state (Jss) by means of a linear regression (cumulative permeated amount $v$ s. time, slope), lag time $\left(\mathrm{T}_{\mathrm{I}}\right)$ (X-intercept), permeability coefficient $\left(K_{\mathrm{p}}=\mathrm{Jss} / \mathrm{C}_{\text {formulation }}\right)$, partition parameter $\mathrm{P}_{1}$ and the apparent length of diffusion parameter $\mathrm{P}_{2}$ (Okamoto et al., 1986; Selzer et al., 2013) were estimated, and compared by the non-parametric analysis (Williams et al., 1992) Kruskal-Wallis oneway Anova test followed by the Kruskal-Wallis multiple-comparison Z-test ( $\alpha=0.05)$.

HPLC analysis. The concentration of forskolin in the receptor solution of the permeation assays was determined using an HPLC Waters instrument, operated at ambient temperature, consisting of an automatic auto sampler system, equipped with UV detector and Spherisorb ODS column $(5 \mathrm{~mm} \times 15 \mathrm{~cm} \times 0.46 \mathrm{~cm})$. The mobile phase was isocratic, i.e. 60 volumes of acetonitrile and 40 volumes of water, which remains constant throughout the whole procedure. The flow rate was set to $0.5 \mathrm{~mL} \cdot \mathrm{min}^{-1}$. The analysis was monitored at $\lambda=210$ $\mathrm{nm}$, sample injection volume was $20 \mu \mathrm{L}$ and run time 10 min. The forskolin content was identified by comparing the retention time and UV spectra. The calibration curve was constructed from linear plots of peak area versus concentration. The calibration curves were prepared in the receptor solution with a forskolin concentration range of 3.2 to $32 \mu \mathrm{g} \cdot \mathrm{ml}^{-1}$.

\section{RESULTS AND DISCUSSION}

\section{Formulation of forskolin-loaded nano-emulsions}

Prior to the preparation of forskolin-loaded nanoemulsions, the solubility of the active substance in Labrafac $\mathrm{CC}^{\circledR}$ (MCT), as well as in MCT/Polysorbate 80 and MCT/Polysorbate 40 mixtures, with ratios of 30/70 and 20/80, was determined. The results (Table 2) revealed that the solubility of forskolin in the MCT/surfactant mixtures was higher than in the oil. Moreover with decrease of MCT (i.e. O/S ratio) an increase of drug solubilization was observed. However, no differences in for- 
Table 2. Solubility of forskolin.

\begin{tabular}{|c|c|c|}
\hline Mixture of Oil and Surfactant & $\mathrm{O} / \mathrm{S}$ ratio & Forskolin $\left[\mathrm{mg} \cdot \mathrm{mL}^{-1}\right]$ \\
\hline Labrafac CC ${ }^{\circ}$ & $100 / 0$ & 3.5 \\
\hline Labrafac CC $\mathrm{CC}^{\circ}$ Polysorbate 80 & \multirow{2}{*}{$30 / 70$} & \multirow{2}{*}{4.5} \\
\hline Labrafac CC ${ }^{\circ}$ /Polysorbate 40 & & \\
\hline 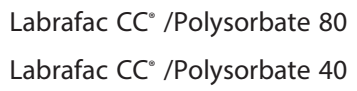 & $20 / 80$ & 6.0 \\
\hline
\end{tabular}

skolin solubility were observed with Polysorbate 80 or Polysorbate 40.

The $\mathrm{O} / \mathrm{W}$ nano-emulsion formation region was determined in the Water/Polysorbate $80 /$ Labrafac $C^{\circledR}$ and Water/Polysorbate 40/Labrafac CC $^{\circledR}$ systems by stepwise addition of water to oil/surfactant mixtures $(\mathrm{O} / \mathrm{S})$ at different ratios, at $25^{\circ} \mathrm{C}$. The results are shown in Fig. 1. O/W nano-emulsions were formed at $\mathrm{O} / \mathrm{S}$ ratios comprised between 10/90 and 30/70. The water concentration in the system was above/exceeded $60 \%$ wt. in the system with Polysorbate 80 (Fig. 1A) and above $50 \%$ wt. in the system with Polysorbate 40 (Fig. 1B). Nano-emulsions became more transparent at high water contents.

Due to the higher forskolin solubility in the oil/surfactant mixture with ratio of $20 / 80$, for further studies, nano-emulsions with $80 \%$ of water and with this oil/surfactant ratio were chosen. Two nano-emulsions containing $0.075 \%$ wt. of forskolin differing in the kind of surfactant used (abbreviated as NE1F with Polysorbate 80 and NE2F with Polysorbate 40), were prepared as described in Section: Incorporation of forskolin into nanoemulsions. The corresponding unloaded-nano-emulsions are designated as NE1 and NE2.

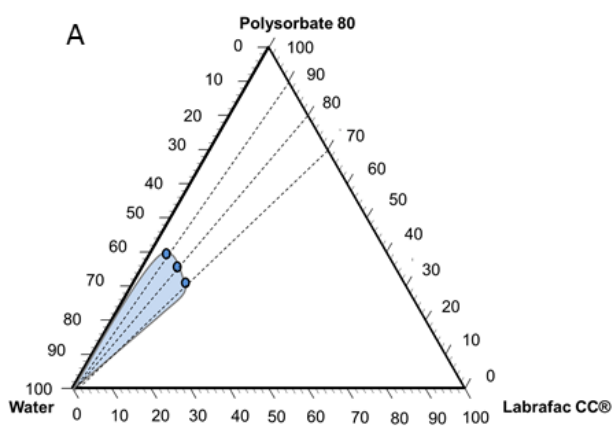

Table 3. Characteristics of the nano-emulsions.

\begin{tabular}{lll}
\hline Formulation & $\begin{array}{l}\text { Mean diameter }(\mathrm{nm}) \\
\pm S . D .(n=3)\end{array}$ & PDI \\
\hline NE1 & $117 \pm 7$ & 0.357 \\
\hline NE2 & $88 \pm 8$ & 0.350 \\
\hline NE1F & $118 \pm 10$ & 0.370 \\
\hline NE2F & $111 \pm 15$ & 0.338 \\
\hline
\end{tabular}

\section{Nano-emulsion characterization}

The results of mean droplet size of the nano-emulsions ( \pm S.D.) and polydispersity index (PDI) characterized by DLS are shown in Table 3. The forskolin-loaded nano-emulsions NE1F and NE2F presented similar droplet diameters of around $118 \pm 10 \mathrm{~nm}$ and $111 \pm 15$ $\mathrm{nm}$, respectively. Incorporation of forskolin did not significantly affect the droplet size in the Polysorbate 80 system, while a slight increase in the droplet size from $88 \pm 8$ to $111 \pm 15 \mathrm{~nm}$ was observed in the Polysorbate 40 system.

The stability of non-loaded nano-emulsions at $25^{\circ} \mathrm{C}$ was assessed by light transmission spectra as a function of time along the sample height. Figure 2 shows that the transmission profiles were roughly flat at the whole height of the samples, indicating that they were homogeneous. The increase in transmission at the meniscus of the sample, as well as at the convex bottom of the cell containing the sample, due to multiple light diffractions, has no physical meaning. The transmission remained practically unchanged in a period of $24 \mathrm{~h}$, indicating that no significant destabilization phenomena, due to creaming or sedimentation, or due to droplet size changes occurred in this period of time.

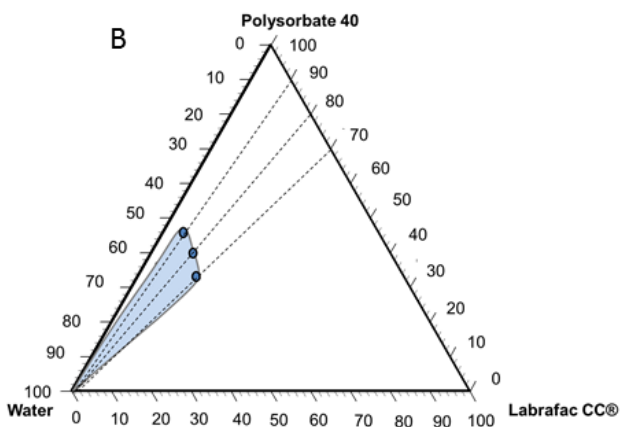

Figure 1. O/W nano-emulsion region in the Water/ Surfactant/Labrafac $\mathrm{CC}^{\oplus}$ (MCT) systems at $25^{\circ} \mathrm{C}$ : (A) Polysorbate 80 and (B) Polysorbate 40 .
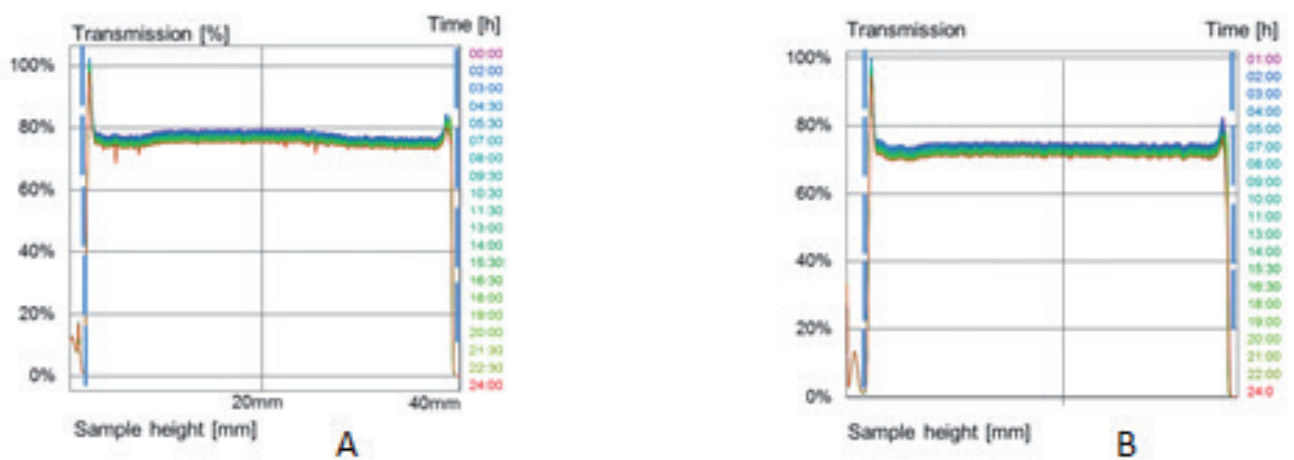

Figure 2. Transmission data of nano-emulsions of the water/surfactant/Labrafac CC (MCT) system with $80 \%$ water and $\mathrm{O} / \mathrm{S}$ ratio of $20 / 80$ along the sample height at different times at $25^{\circ} \mathrm{C}$ : (A) Polysorbate 80 system (NE1) and (B) Polysorbate 40 system (NE2). 


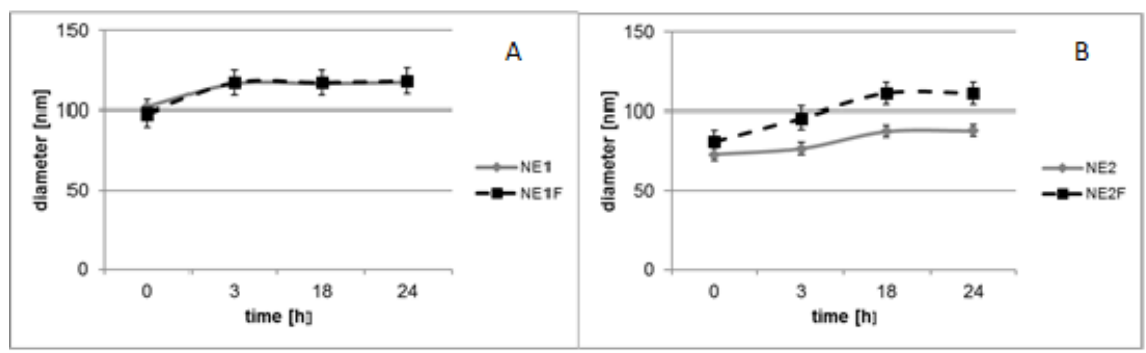

Figure 3. Droplet size of nano-emulsions of the water/ surfactant/Labrafac CC ${ }^{\circledR}$ (MCT) system, with $80 \%$ water and O/S ratio of $20 / 80$ without forskolin (NE1 and NE2) and with forskolin (NE1F and NE2F) as a function of time: (A) Polysorbate 80 system and (B) Polysorbate 40 system.

Table 4. Mean and standard deviation of permeation parameters $(n=4)$.

\begin{tabular}{llllll}
\hline Formula & $\begin{array}{l}\mathrm{s}_{\text {ss }} \\
\left(\mu \mathrm{g} \cdot \mathrm{cm}^{-2} \cdot \mathrm{h}^{-1}\right)\end{array}$ & $\begin{array}{l}\mathrm{T}_{\mathrm{L}} \\
(\mathrm{h})\end{array}$ & $\begin{array}{l}K_{\mathrm{p}} \cdot 10^{3} \\
\left(\mathrm{~cm} \cdot \mathrm{h}^{-1}\right)\end{array}$ & $\begin{array}{l}\mathrm{P}_{1} \\
(\mathrm{~cm})\end{array}$ & $\begin{array}{l}\mathrm{P}_{2} \cdot 10^{2} \\
\left(\mathrm{~h}^{-1}\right)\end{array}$ \\
\hline NE1F & $6.91 \pm 0.75$ & $8.82 \pm 0.90$ & $9.21 \pm 1.00$ & $0.49 \pm 0.10$ & $1.90 \pm 0.002$ \\
\hline NE2F & $4.92^{*} \pm 0.44$ & $2.75^{*} \pm 0.36$ & $6.55^{*} \pm 0.59$ & $0.108^{*} \pm 0.019$ & $6.13^{*} \pm 0.80$ \\
\hdashline Labrafac CC & $6.07 \pm 0.53$ & $4.25 \pm 1.21$ & $8.10 \pm 0.70$ & $0.210 \pm 0.080$ & $4.13 \pm 1.00$ \\
\hline
\end{tabular}

${ }^{*} p<0.05$ with NE1F

Stability of the forskolin-loaded and unloaded nanoemulsions was also determined by measurements of droplets size (by DLS) with time. Figure $3 \mathrm{~A}$ shows that in the system with Polysorbate 80, a slight increase in the droplet size was produced during the first three hours and afterwards the size was constant during the experimental time of 24 hours. The size and the evolution of size with time of the unloaded and loaded nano-emulsions of this system were identical. Also, for the nano-emulsions with Polysorbate 40 (Fig. 3B), the data confirm the stability of the systems for 24 hours, at $25^{\circ} \mathrm{C}$.

\section{Permeation results}

Permeation profiles of forskolin from the two nano-emulsions and Labrafac $\mathrm{CC}^{\circledR}(\mathrm{MCT})$ were similar (Fig. 4). The flux was higher for NE1F than for NE2F. The percentage of permeation after $24 \mathrm{~h}$ was high $(69.92 \pm 8.89 \%, \quad 71.49 \pm 7.11 \%$ and $83.48 \pm 7.41 \%$, for NE1F, NE2F and MCT, respectively). These results are similar to those obtained in our previous work with emulsion composed of MCT but with different surfactant and droplet size (Sikora et al., 2015). We hypothe-

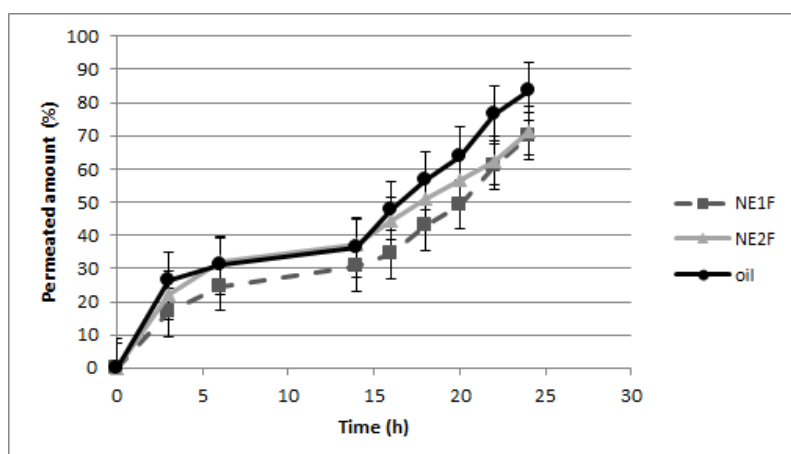

Figure 4. Skin permeation profile of forskolin from nano-emulsions and an oil solution.

NE1F: Polysorbate 80 system. NE2F: Polysorbate 40 system. size a rapid penetration of forskolin through the stratum corneum (SC) facilitated by the high lipophilicity of the molecule $(\log \mathrm{P}=3.89)$ and adequate molecular weight $\left(410.50 \mathrm{~g} \cdot \mathrm{mol}^{-1}\right)$. But as the skin is composed of the lipophilic SC and hydrophilic viable layers of epidermis, the partitioning of forskolin into the layers becomes difficult. Therefore, forskolin would make a reservoir in SC and after approximately $10 \mathrm{~h}$, it would start a second step of permeation from a saturated SC where forskolin would be accumulated. This second step is possibly due to alterations in the skin mediated by the components of the formulations, and basically by the Labrafac $\mathrm{CC}^{\circledR}$ oil. Kandimala and coworkers (2010) also described a twostep profile in the permeation of melatonin in the presence of saturated and unsaturated fatty alcohols. However, it showed a higher flux in the first step than in the second. This decrease in the second step was attributed to the penetration of polar formulation components in the SC decreasing the formulation/skin partition of melatonin, which is not the case in our study.

According to the permeation parameters (Table 4) obtained from the second step of the profile, NE1F presented higher values $(p<0.05)$ than NE2F and Labrafac $\mathrm{CC}^{\circledR}$, except for the $\mathrm{P}_{2}$ parameter. Then, the substitution of Polysorbate 40 for Polysorbate 80 in the nano-emulsions increased the percutaneous penetration of forskolin through human skin. If we calculate the $K_{p}$ enhancement ratio (Williams and Barry, 1991) of NE1F in respect to Labrafac $\mathrm{CC}^{\circledR}$, the value is approximate to 1 (1.14). In this way, the permeability coefficients are very similar and would be in accordance with the high lipophilicity of forskolin. However, the in vivo application of forskolin in MCT would represent a non-acceptable cosmetic formulation, due to the oily feeling.

On the other hand, the lipids of the NE2F (Labrafac $C^{\circledR}$ ) and surfactant Polysorbate 40 interact in the same order as the oil alone did with the intercellular lipid matrix, increasing the disruption of the packed lipid regions and rising the diffusion of forskolin through the skin and reflected in the $\mathrm{P}_{2}$ parameter. However, when comparing the permeability coefficient of forskolin for 
$\mathrm{NE} 1 \mathrm{~F}$ in respect to NE2F $\left(9.21 \cdot 10^{-3} \pm 1.00 \cdot 10^{-3} \mathrm{~cm} \cdot \mathrm{h}^{-1}\right.$ vs. $\left.6.55 \cdot 10^{-3} \pm 0.59 \cdot 10^{-3} \mathrm{~cm} \cdot \mathrm{h}^{-1}\right)$ the difference can be attributed to the relatively higher $\mathrm{P}_{1(\mathrm{NE} 1 \mathrm{~F})} / \mathrm{P}_{1(\mathrm{NE} 2 \mathrm{~F})}$ ratio (4.53) with respect to the $\mathrm{P}_{2(\mathrm{NE} 1 \mathrm{~F})} / \mathrm{P}_{2(\mathrm{NE} 2 \mathrm{~F})}$ ratio $(0.30)$. According to this, and taking into account that the composition of the formulations are the same (except for the type of surfactant), and also the droplet size and the solubility in the Polysorbate/Labrafac $C^{\circledR}$ mixture are similar, the differences observed in the permeation should be attributed to higher affinity of forskolin for the vehicle in $\mathrm{NE} 2 \mathrm{~F}$ with respect to the skin and giving a lower value of the $P_{1}$ parameter. The nano-emulsion of NE2F presented a similar behavior as MCT did in skin permeation of forskolin: in those formulations the diffusion through the skin layers is higher and also presented lower partition coefficient of forskolin skin/vehicle retaining the actives in the vehicle. The observed results can be explained by differences in hydrophilicity and the structure of the alkyl chain of the surfactants used, and related to the higher HLB number of Polysorbate 40 with respect to Polysorbate 80 (15.6 vs. 15, respectively) by which forskolin would have more affinity. Wu and coworkers (1996) studied the effect of the kind of surfactant on captopril percutaneous absorption. Among the nonionic surfactants (Polysorbates) used, the polyoxyethylene sorbitan monolaurate (Polysorbate 20), the most hydrophilic one $(\mathrm{HLB}=16.7)$, had the greatest impact on the flux of the active substance. On the other hand, in the case of Polysorbate with longer alkyl chain, the structure of the chain seems to be more significant than the surfactant hydrophilicity. Molecules with saturated fatty acids, e.g. Polysorbate 40, despite the higher hydrophilicity, have less pronounced effect than unsaturated ones (Polysorbate 80), probably due to a lesser ability to disrupt the lipid packing of stratum corneum. In summary, active skin permeation is related to the structure of the alkyl chain of the surfactants, their hydrophilicity and the affinity of the actives to the vehicle.

In the case of forskolin, both Polysorbates used act as skin permeation enhancers. That means that emulsions composed of caprylic/capryc triglycerides and different surfactants can be considered as good carriers for forskolin delivery systems into the skin. However, it should be noted that maximum forskolin permeation was obtained using the nano-emulsion containing Polysorbate 80 .

\section{CONCLUSIONS}

Kinetically stable, forskolin-loaded $\mathrm{O} / \mathrm{W}$ nano-emulsions $(0.075 \%$ wt.), based on caprylic/capryc triglycerides and stabilized with Polysorbate 80 or Polysorbate 40 were obtained, with droplet diameters around 118 $\mathrm{nm}$ and $111 \mathrm{~nm}$, respectively. Nano-emulsion droplet size was not changed by incorporation of forskolin in the system with Polysorbate 80 , but a slight increase in size was observed for the Polysorbate 40 system. The in vitro skin permeation studies through human skin have shown that similar amounts of forskolin penetrate from both, the nano-emulsion formulations and from the oil solution. However, the substitution of Polysorbate 40 for Polysorbate 80 in the nano-emulsions increases the percutaneous penetration of forskolin through the skin. Nano-emulsions, based on caprylic/capryc triglycerides can be considered as good carriers for controlled release of forskolin for topical application.

\section{Acknowledgement}

The research (work) was supported by the European Union through the European Social Fund within "Cracow University of Technology development program - top quality teaching for the prospective Polish engineers; University of the 21 st century" project (contract no.UDA-POKL.04.01.01-00-029/10-00). Financial support from the Spanish Ministry of Economy and Competitiveness, MINECO (grant CTQ 2011-29336-CO3-01 and CTQ 2011-29336-CO3-03) is also acknowledged. The authors thank Dr Luís Asmarats from Clínica Sagrada Familia (Barcelona, Spain) for providing skin samples.

\section{REFERENCES}

Akhtar N, Rehman MU, Khan HMS, Rasool F, Saeed T, Murtaza G (2011) Penetration enhancing effect of Polysorbate 20 and 80 on the in vitro percutaneous absorption of L-ascorbic acid. Tro J Pharm Res 10: 281-288. doi: 10.4314/tjpr.v10i3.1

Amaro-Ortiz, Yan B, D’Orazio JA (2014) Ultraviolet radiation, aging and the skin: prevention of damage by topical cAMP manipulation. Molecules 19: 6202-6219. doi: 10.3390/molecules19056202.

Bagchi D, Preuss HG (2012) Obesity: Epidemiology, Pathophysiology and Prevention. Taylor and Francis Group

Caldero G, Garcia-Celma MJ, Solans C (2011) Formation of polymeric nano-emulsions by a low-energy method and their use for nanoparticle preparation. J Colloid Interface Sci 353: 406-411. doi: 10.1016/j. jcis.2010.09.073

Chaudhri N, Soni GC, Prajapati SK (2015) Nanotechnology: an advance tool for nano-cosmetics preparation. IJPRR 4: 28-40

Ciotonea C, Cernătescu C (2010) Biological active effects of Foskolin extract. Buletinul Institutului Politehnic DIN LASI 4: 95-106

Fernandez P, Andre V, Rieger J, Kühnle A (2004) Nano-emulsion formation by emulsion phase inversion. Colloids Surf $A$ 251: 53-58. doi: 10.1016/j.colsurfa.2004.09.029

Fornaguera C, Dols-Perez A, Caldero G, Garcia-Celma MJ, Camarasa J, Solans C (2015) PLGA nanoparticles prepared by nano-emulsion templating using low-energy methods as efficient nanocarriers for drug delivery across the blood-brain barrier. J Control Release 211: 134-143. doi: 10.1016/j.jconrel.2015.06.002

Graca M, Bongaerts JH, Stokes JR, Granick S (2007) Friction and adsorption of aqueous polyoxyethylene (Tween) surfactants at hydrophobic surfaces. J Colloid Interface Sci 315: 662-670

Gugliemini G (2006) Evaluating droplet size in nanoemulsions from a novel emulsifier system. Cosmetics \& Toiletries 121: 67-72

Kandimalla KK, Babu RJ, Singh M (2010) Biphasic flux profiles of melatonin: the Yin-Yang of transdermal permeation enhancement mediated by fatty alcohol enhancers. J Pharm Sci 99: 209-218. doi: 10.1002/jps.21812

Kothekar S, Waghmare J, Momin S (2006) Rationalizing and Producing Nano-emulsions for Personal Care. Cosmetics \& Toiletries 121: 51-56

Nokhodchi A, Shokri J, Dashbolaghi A, Hassan-Zadeh D, Ghafourian T, Barzegar-Jalali M (2003) The enhancement effect of surfactants on the penetration of lorazepam through rat skin. Int J Pharm 250: 359-369. doi: 10.1016/S0378-5173(02)00554-9

Okamoto H, Kamatsu H, Hashida M, Sezaki H (1986) Effects of $\beta$-cyclodextrin and di-o-methyl- $\beta$-cyclodextrin on the percutaneous absorption of butylparaben, indomethacin and sulfanylic acid. Int J Pharm 30: 34-35

Pandey A, Mittal A, Chauhan N, Alam S (2014) Role of surfactants as penetration enhancer in transdermal drug delivery system. $J \mathrm{Mol}$ Pharm Org Process Res 2: 113. doi: 10.4172/2329-9053.1000113

Passeron T, Namiki T, Passeron HJ, Le Pape E, Hearing VJ (2009) Forskolin protects keratinocytes from ultraviolet (UV) B-induced apoptosis and increases DNA repair independent of its effects on melanogenesis. J Invest Dermatol 129: 162-166. doi: 10.1038/ jid.2008.182

Porras M, Solans C, Gonzalez C, Gutierrez JM (2008) Properties of water-in-oil (W/O) nanoemulsions prepared by a low-energy emulsification method. Colloids Surf A 324: 181-188. doi: 10.1016/j.colsurfa.2008.04.012

Selzer D, Abdel-Mottaleb MMA, Hahn T, Schaefer UF, Neumann D (2013) Finite and infinite dosing: difficulties in measurements, evaluations and predictions. Adv Drug Deliv Rev 65: 278-294. doi: 10.1016/j.addr.2012.06.010

Sikora E, Llinas M, Garcia-Celma MJ, Escribano E, Solans C (2015) Transdermal delivery of forskolin form emulsions differing in droplet size. Colloids Surf B 126: 541-545. doi: 10.1016/j.colsurfb.2015.01.008 
Som I, Bhatia K, Yasir M (2012) Status of surfactants as penetration enhancers in transdermal drug delivery. J Pharm Bioall Sci 4: 2-9. doi: 10.4103/0975-7406.92724

Spry ML, Vanover JC, Scott T, Abona-Ama O, Wakamatsu K, Ito S, D’Orazio JA (2009) Prolonged treatment of fair shimed mice with topical forskolin causes persistent tanning and UV protection. Pigment Cell Melanoma Res 22: 219-229. doi: 10.1111/j.1755148X.2008.00536.x

Usón N, Garcia MJ, Solans C (2004) Formation of water-in-oil (W/O) nano-emulsions in a water/mixed non-ionic surfactant/oil systems prepared by a low-energy emulsification method. Colloids Surf $A$ 250: 415-421. doi:10.1016/j.colsurfa.2004.03.039
Williams AC, Barry BW (1991) Terpenes and the lipid-protein-partitioning theory of skin penetration enhancement. Pharm Res 8: 17-24

Williams AC, Cornwell PA, Barry BW (1992) On the non-gaussian distribution of human skin permeabilities. Int J Pharm 86: 69-77. doi: 10.1016/0378-5173(92)90032-W

Wohlfart S, Gelperina S, Kreuter J (2012) Transport of drugs across the blood-brain barrier by nanoparticles. I Control Release 161: 264 273. doi: 10.1016/j.jconrel.2011.08.017

Wu P-Ch, Huang Y-B, Lin H-H, Tsai Y-H (1996) In vitro percutaneous absorption of captopril through excised rabbit skin. Int J Pharm 143: 119-123. doi: 10.1016/S0378-5173(96)04680-7 